\title{
Epidemiology of Childhood Guillain Barré Syndrome in Yemen
}

\author{
Hadi Mohammed Mujlli*, Abdulrahman Sallam Al-kubati, Abdula Mhammed Mojali, \\ Amin Mohamed Abdurab \\ Medical Department, Medical College, Thamar University, Dhamar, Yemen \\ Email: *dr.hadimujlli@gmail.com
}

Received 15 February 2016; accepted 29 February 2016; published 4 March 2016

Copyright (C) 2016 by authors and OALib.

This work is licensed under the Creative Commons Attribution International License (CC BY). http://creativecommons.org/licenses/by/4.0/

(c) (i) Open Access

\section{Abstract}

Background: GBS (Guillain-Barré Syndrome) is one of the most frequently seen acute polyneuropathy encountered in neurology practice and characterized by progressive motor weakness and loss of reflexes. Objective: The main objectives were to determine the incidence of Guillain-Barré Syndrome, distribution of paralysis and hospital outcome of patients within 60 days of admission. Material \& methods: The records of all patients followed with flaccid paralysis to the surveillance sites in 11 through the WHO program for Acute Flaccid governorates in Yemen. From 21th September 2004 to 20th September 2013 were reviewed. Those patients suspected to be GBS were examined by a consultant neurologist and pediatric to confirm the diagnosis. At the time of admission specific form was designed to record demographic characteristics, clinical finding and presentation of paralysis. All patients follow up for 60 days. Collected data was entered to Epi info statistical method used by AFP program. Results: During the study period, 808 patients were diagnosed a GBS. Of this $483(60 \%)$ were males and $325(40 \%)$ were females. The age of the patients was ranged (between 1 to 15 years), most of them 457 (57\%) were young children of $\leq 5$ years old. The overall incidence was $2.8 / 100,000$ population. The outcome of patients showed that 284 (35\%) had residual paralysis. $469(58 \%)$ recovered completely, $7(1 \%)$ was lost and $48(6 \%)$ patients died within 60 days of follow up. Conclusion: This study confirms that Guillain-Barré Syndrome is the most common causes of Acute Flaccid Paralysis in Yemen with high morbidity in children.

\section{Keywords}

Guillain-Barré Syndrome (GBS), Flaccid Paralysis, Governorate (Gov.), Children

Subject Areas: Neurology, Public Health

\footnotetext{
"Corresponding author.
} 


\section{Introduction}

Guillain-Barré Syndrome (GBS) is an acute inflammatory demyelinating polyradiculoneuropathy (AIDP). It starts by paresthesia in the lower-extremity followed by ascending symmetric muscle weakness [1].

GBS is an acute immune-mediated polyradiculoneuropathy characterized by symmetric ascending weakness and spontaneous remission, it is postulated to be acute immune disease [2] [3]. It is the most common cause of acute flaccid paralysis in children which often leads to respiratory and bulbar compromise [3] [4]. GBS often follows an antecedent gastrointestinal or respiratory illness, but in rare cases follows vaccination [5].

The etiology of GBS is definitely unknown. It's considered to be a post-infectious disease. Studies are shown that almost two-thirds of patients reporting infectious illnesses are prior to the onset of GBS [6] [7]. Antiganglioside antibodies are detected at least in one third of patients [8]. These antibodies appear to cross react with antigen in the lipopolysaccharide of some antecedent infective agents, providing a possible mechanism for the disease [6] [9].

Epidemiological studies from different areas estimate that the incidence of GBS ranges between 1 and 2/100,000 [10] [11]. In the United State of America, annual incidence of GBS is $1.2-3 / 100,000$ inhabitants. They find that the incidence increases with increasing age [8] [9]. A high incidence although is reported among young adults [12].

Based on clinical features and electro diagnostic criteria GBS can be classified into heterogeneous subgroups of syndromes such as acute inflammatory demyelinating polradiculoneuropathy (AIDP), acute motor axonal neuropathy (AMAN), acute motor-sensory axonal neuropathy (AMSAN) and Miller-Fisher syndrome(MFS).

In European and US, AIDP subgroup of GBS is the most prevalent form reached to (85\% to $90 \%$ ) of cases while, in Asian studies this subtype presents only in about 53\% of the cases [13]. In contrast, AMAN and AMSAN subtypes occur mainly in northern China, Japan, and Mexico, and they comprise $5 \%-10 \%$ of GBS cases in the United States [14]. Incidence and outcome of GBS in Yemen are not known so this study is the first epidemiological study to elaborate this disease in Yemen.

\section{Material \& Methods}

Study design: This was cross sectional retrospective study, done in 11 governorates (Aden, Al-hudaidah, Hadramot-Almukllaa, Sayeuon, Ibb, Saadah, Taiz, Thamar, Hajjah, Sanaa City, Sanaa Governorate) in Yemen. The records of all patients presented to surveillance sites (main hospitals) with Acute Flaccid Paralysis (AFP) through 21st Sep. 2004 to 20th Sep. 2013 were reviewed. Patients suspected to be GBS was subjected to neurological examination by a team of neurologist and pediatrician whom were trained by special training program for AFP at WHO office in ministry of health in Sana'a. Patients with clinically diagnosed as GBS were included in this study. Patients was included if presented with acute attack, his/her age between 1 - 15 years old, came from one of above governorates [11] and Yemeni. We excluded chronic cases of GBS, his/her age more than 15 years or less than 1 year and not from Yemen. Special form was design to collect demographic characters including (age, sex, residency), preceding events, presentation of paralysis of the upper and/or lower limbs and all other clinical data. EMG and NCS were done for most of the cases to prove the diagnosis of GBS. Special follow up sheet was prepared to record the outcome of patients within 60 days of admission. Informed consent from child's parents was obtained from every case participated in this study.

Statistical analysis: All data was entered into Epi Info. For statistical analysis of age, sex distribution and paralysis residual/ non residual improvement's.

\section{Results}

In this study, 808 patients were confirmed clinically to have GBS. 483 (60\%) of them were males and 325 (40\%) were females given the ratio of 3:2 respectively. However in Aden Governorate both sexes equally affected as shown in Table 1. The overall incidence of GBS was 2.8/100,000 population.

Age distribution of the patients is shown in Table 2. Most cases 457 (57\%) of GBS occurred in children below 5 years of age compared to children of 5 years old or more were 351 (43\%) found to be affected, most of them from Aden and Ibb Governorates.

Patients with GBS from different governorates were followed up within 60 days of admission and outcome of them is seen in Table 3. Complete improvement without residual effect was found in 469 (58\%) patients, most of them from saadah and Sana'a governorates. 284 (35\%) patients found to have residual effect interestingly. 
Table 1. Sex distribution of children with GBS in the different governorates in Yemen.

\begin{tabular}{cccc}
\hline Governorate & Male & Female & Total \\
\hline Aden & $21(50 \%)$ & $21(50 \%)$ & 42 \\
Al-Hudaidah & $73(57 \%)$ & $55(43 \%)$ & 128 \\
H. Amuklla & $15(48 \%)$ & $11(42 \%)$ & 26 \\
H. Sayeuon & $19(53 \%)$ & $17(43 \%)$ & 36 \\
Ibb & $59(67 \%)$ & $29(33 \%)$ & 88 \\
Saadah & $66(63 \%)$ & $39(37 \%)$ & 105 \\
Taiz & $47(57 \%)$ & $35(43 \%)$ & 82 \\
Thamar & $52(64 \%)$ & $21(36 \%)$ & 89 \\
Hajjah & $49(60 \%)$ & $33(40 \%)$ & 82 \\
Sanaa City & $51(59 \%)$ & $36(41 \%)$ & 87 \\
Sana’a & $31(61 \%)$ & $20(39 \%)$ & 51 \\
Grand Total & $483(60 \%)$ & $325(40 \%)$ & 808
\end{tabular}

Table 2. Age distribution of children with Guillian Barré Syndrome in the different governorates in Yemen.

\begin{tabular}{ccc}
\hline Governorate & $\leq 5$ years & $\geq 5$ years \\
\hline Aden & $23(55 \%)$ & $19(45 \%)$ \\
Al-Hudaidah & $83(65 \%)$ & $45(35 \%)$ \\
H. Amuklla & $46(57 \%)$ & $35(43 \%)$ \\
H. Sayeuon & $13(50 \%)$ & $13(50 \%)$ \\
Ibb & $18(50 \%)$ & $18(50 \%)$ \\
Saadah & $47(57 \%)$ & $35(43 \%)$ \\
Taiz & $35(40 \%)$ & $53(60 \%)$ \\
Thamar & $63(60 \%)$ & $42(40 \%)$ \\
Hajjah & $30(59)$ & $21(41 \%)$ \\
Sanaa City & $57(66 \%)$ & $30(34 \%)$ \\
Sana’a & $42(51 \%)$ & $40(49 \%)$ \\
Grand Total & $457(57 \%)$ & $351(43 \%)$ \\
\hline
\end{tabular}

Table 3. Outcome of GBS patients within 60 days of admission.

\begin{tabular}{cccccc}
\hline Governorates & Residual & Non-residual & Lost & Died & Total \\
\hline Aden & 13 & 27 & 0 & 2 & 42 \\
Al-Hudaidah & 85 & 34 & 0 & 9 & 128 \\
H-Almuklla & 4 & 21 & 0 & 1 & 26 \\
H-Sayuon & 13 & 18 & 3 & 2 & 36 \\
Saadah & 29 & 75 & 0 & 5 & 105 \\
Taiz & 24 & 53 & 0 & 12 & 82 \\
Ibb & 24 & 52 & 0 & 3 & 88 \\
Thamar & 28 & 50 & 1 & 4 & 81 \\
Hajjah & 32 & 45 & 3 & 6 & 82 \\
Sana’a city & 13 & 65 & 0 & 3 & 87 \\
Sana'a & 19 & 29 & $7(1 \%)$ & $28(6 \%)$ & 808 \\
Grand Total & $283(35 \%)$ & $469(58 \%)$ & & & 51 \\
\hline
\end{tabular}


These cases came from two neighbor governorates (Al-Hudaidah, and Hajjah). 28 (6\%) patients died and 7 (1\%) lost from follow up. As shown in Table 3 and Figure 1.

\section{Discussion}

Guillain-Barré Syndrome is a disorder in which the body's immune system attacks the peripheral nerves leading to weakness and loss of sensation. These sensation can quickly spread, eventually paralyzing the whole body. Luckily, Guillain-Barré Syndrome is uncommon, affecting only 1 or 2 people per 100,000 [15]. In this study the mean annual incidence of Guillain-Barré Syndrome was 2.8/100,000 population (95\% confidence intervals 2.10 to 3.71 ) per 100,000 children under 15 years old of age. Epidemiological studies from various regions have reported an annual incidence of between 0.16 - 2 cases per 100,000 population [16]-[18]. The high incidence in our study could be related to the high frequency of gastro intestinal and respiratory infection among this age group. The other reason for this high incidence may be related to outbreak of poliomyelitis in the country during the study period. Interestingly western governorates (Al- Hudaidah \& Hajaah) found to have higher incidence of GBS compared to both Central and Northern ones. This geographic variation in the incidence of disease in Yemen may be related to environmental factors that may play a role in the development of the diseases. Further study is needed to clarify the causes behind this high incidence.

In this research our findings showing slightly more male individuals affected than females 3:2 in which 808 patients 483 (60\%) males and 325 (40\%) females in which 57\% of males present in Al-Hudaidah Gov. and 43\% of females in the same Gov. and 50\% males, 50\% females in Aden Gov. while its 61\% males and 39\% females in Sana'a. our results correlated with (Hughes et al.) That show The incidence of disease is $1-2$ cases per 100.000 population per year. Males are affected more than females. Male-female ratio is 1.25:1 and, it occurs more common in young adults and after 55 years old, though it may be seen at every age. Different cases are reported between 8 month and 81 year old [19]. Current epidemiological studies suggest an incidence of between 1 and 2/100 000 with slightly, more male individuals affected than females [7].

Our study showing the gender distribution and percentage more in children under 5 years old; 808 patients with the age range of 457 (57\%) patients $\leq 5$ years old mainly in Sanaa city and Alhudaidah Gov., 357 (43\%) patients $\geq 5$ years old, mainly in Ibb and Hadramot-Almukllaa. In accordance with other reports, children 1 - 4 years

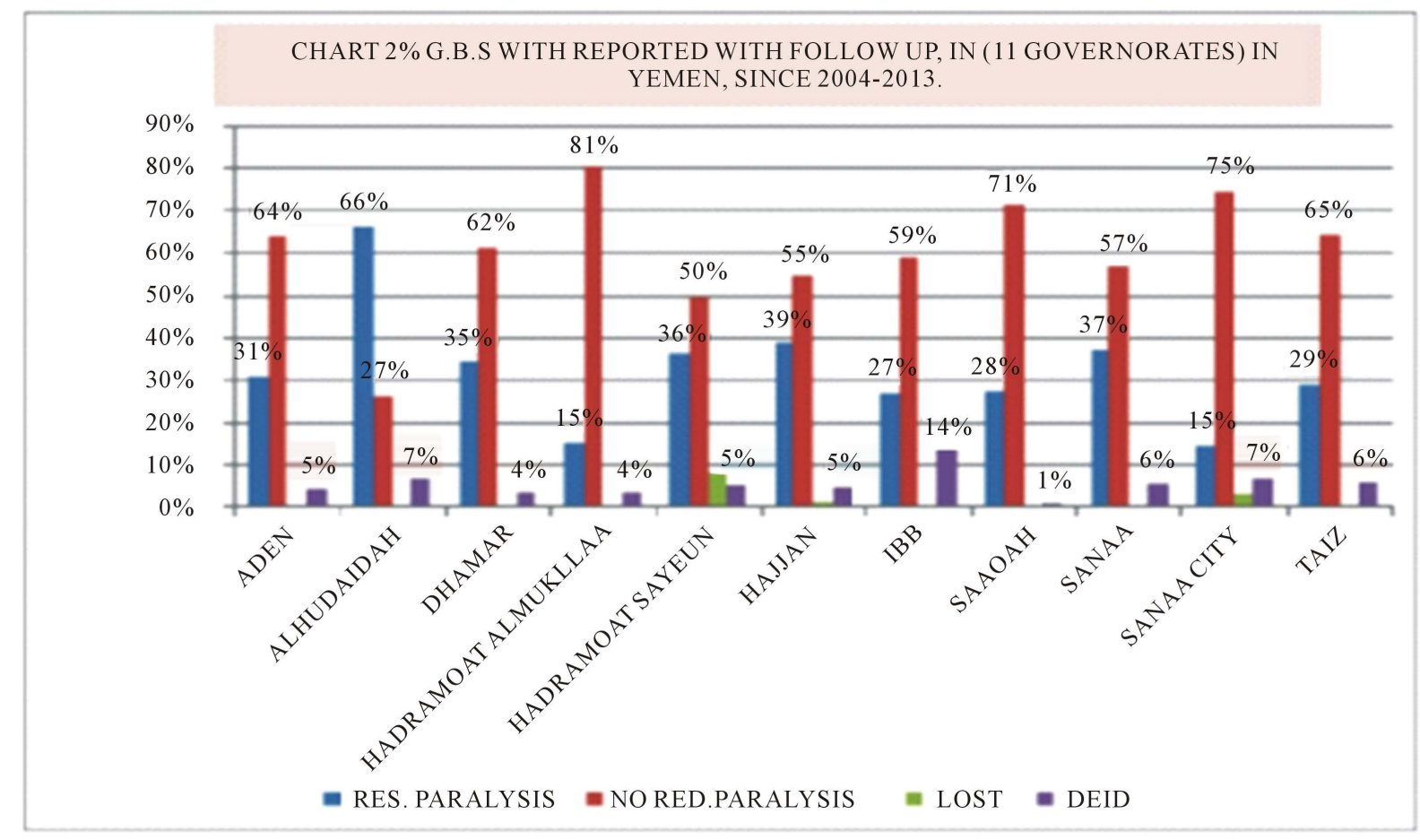

Figure 1. GBS was reported with residual paralysis, no residual paralysis, lost and died in 11 governorates in Yemen since 2004-2013. 
old were the most commonly affected age group with GBS [18] [20]. GBS in children under 5 years old believed to be due to their relatively high susceptibility to infections in this age group and the increased susceptibility to the young myelinated peripheral nerves to demyelination [21] [22]. GBS has been reported in all age groups, with the syndrome occurring at any time between infancy and old age. In the United States, the syndrome's age distribution seems to be bimodal, with a first peak in young adulthood (age 15 - 35 yrs) and a second, higher one in elderly persons (age 50 - 75 yrs). Infants appear to have the lowest risk of developing GBS [23].

In this research GBS cases 35\% still have paralysis at 60 days follow up clinically by a consultant neurologist and pediatrics consultation, in 11 Gov. 284 (35\%) patients not improved (residual) mainly in Al-Hudaidah and Hajah Gov., 469 (58\%) patients improved (non-residual) mainly in Sana'a city, Aden and Saddah Gov., 7 (1\%) patients lost and 28 (6\%) patients died, mainly in Ibb and Al-Hudaidah Gov. However, since the data were collected for the purpose of acute flaccid surveillance as a strategy for detecting cases of poliomyelitis, the study provides limited information about the clinical features and subtypes of disease. In related to other (Korinthenberg R et al.) reports, Follow-up investigation demonstrated that 44\% of GBS cases still had persistent motor weakness at 60 days after onset. The presence of motor weakness at 60 days is one of the Criteria that the poliomyelitis eradication program uses for case confirmation in absence of adequate stool samples (2 stool samples taken $24 \mathrm{~h}$ apart within 2 weeks of muscular weakness onset). High rate of residual paralysis among GBS cases 60 days after paralysis onset may result in a misclassification Of GBS cases as confirmed polio and underscores the importance of virus isolation from adequate stools as the preferred method to confirm cases of polio [24]. The syndrome often begins with symmetric weakness of lower limbs [10]. However, ascending quick progression of weakness develops total motor paralysis and death may occur due to respiratory insufficiency [27].

As it might be expected from a study that is primarily concerned about AFP surveillance as a sensitive measure to detect cases of poliomyelitis, specific details about the progression pattern of weakness, sensory involvement, and dysautonomia in patients with GBS were not recorded in the study. It also repeats the importance of a standardized clinical investigation of all cases of AFP in children, which can be achieved only through a well- organized coordination between epidemiologists, neurologists, pediatricians, virologists, and specialists in rehabilitation [26]. Clinical investigation emphasize that stool specimen collection for virus isolation is superior to clinical examinations for residual paralysis 60 days after onset for case confirmation, particularly when the incidence of polio is low. Each case of GBS should be considered a probable case of polio and should be subjected to adequate investigation, including collection of stool samples as early as possible after paralysis onset.

Prevalence of Guillain-Barré syndrome in Yemen about 1 in 100,000 NWHIC (Yemen 200:20,024,8672) [27]. This is important, as poliomyelitis can easily be misdiagnosed as GBS, as happened during the poliomyelitis outbreak in Finland 1984 [23]. West governorates as Al-Hudaidah have a statistically significant higher incidence of GBS compared to both Central and Northern ones, but the south governorates as Aden and Al-Mukalla have no significant although it have the same hot climate like Alhudaidah . Although no specific reason was found, geographic variation in the incidence of disease in Yemen may be due to differences in the infection rates and climate among the different regions. In accordance to other studies that have addressed the seasonality in the incidence of GBS, only a few demonstrated a significant seasonal trend. The lack of clear seasonal association may be due to the fact that the respiratory and enteric infections that precede GBS have opposite seasonal patterns Many studies have addressed the seasonality in the incidence of GBS, only a few demonstrated a significant seasonal trend. The lack of clear seasonal association may be due to the fact that the respiratory and enteric infections that precede GBS have opposite seasonal patterns [28]. However, IVIG therapy remains largely unavailable in many governorates in Yemen. Further research's about GBS and TN in Yemen are needed to develop the diagnostic and treatment methods.

\section{Conclusion}

Guillain-Barré Syndrome is a neurological emergency disorder. Early recognition and management for patients with this disorder may save their life and prevent lifelong disabilities. This research confirms that GBS \& TN are the common cause of AFP in Yemen. Also it opens the door for more researches for GBS in Yemen.

\section{Acknowledgements}

Great thanks for the staff of AFP program of WHO in Ministry of Health in Yemen Sana'a for the help to collect the data and follow up supervisors. We particularly thank the national staff of the Ministry of Health staff in- 
volved in this effort, whose commitment, and creativity has made possible the objective to eradicate poliomyelitis from this continent, and all clinicians and neuropediatricians participating in the eleven governorates study.

\section{References}

[1] Biller, J. (2012) Approach to the Patient with Acute Muscle Weakness. In: Horak, H.A., Ed., Practical Neurology, 4th Edition, 304-309.

[2] Jacobs, B.C., Rothbarth, P.H., Vandermeche, F.G.A., et al. (1998) The Spectrum of Antecedent Infections in GuillainBarre Syndrome. Neurology, 51, 1110-11115. http://dx.doi.org/10.1212/WNL.51.4.1110

[3] Guillain, G., Barré, J. and Strohl, A. (1916) Sur un syndrome de radiculo-nevrite avec hyperalbuminose du liquid cephalorachidien sans reaction cellulaire. Remarquessur les characters cliniqueetgraphique des reflexes tendinaux. Bulletins et Memories de la Societe Medicale des Hopitaux de Paris, 40, 1462-1470.

[4] Alter, M. (1990) The Epidemiology of Guillain-Barré Syndrome. Annals of Neurology, 27, S7-S12. http://dx.doi.org/10.1002/ana.410270704

[5] Ouvrier, R.A., McLeod, J.G. and Pollard, J.D. (1999) Guillain Barré Syndrome. In: Ouvrier, R.A., McLeod, J.G. and Pollard, J.D., Eds., Peripheral Neuropathyin Childhood, 2nd Edition, Mac Keith Press, London, 42-54.

[6] Yuki, N. (1997) Molecular Mimicry between Gangliosides and Lipopolysaccharides of Campylobacter jejuni Isolated from Patients with Guillain-Barré Syndrome and Miller Fisher Syndrome. The Journal of Infectious Diseases, 176, S150-S153. http://dx.doi.org/10.1086/513800

[7] Korinthenberg, R. and Mönting, J.S. (1996) Natural History and Treatment Effects in Guillain-Barré Syndrome: A Multi-Centre Study. Archives of Disease in Childhood, 74, 281-287. http://dx.doi.org/10.1136/adc.74.4.281

[8] Kaplan, J.E., Katona, P., Hurwitz, E.S., et al. (1982) Guillain-Barré Syndrome in the United States, 1979-1980 and 1980-1981. Lack of an Association with Influenza Vaccination. JAMA, 248, 698-700. http://dx.doi.org/10.1001/jama.1982.03330060038030

[9] Shahar, E. and Leiderman, M. (2003) Outcome of Severe Guillain-Barré Syndrome in Children: Comparison between Untreated Cases versus Gamma-Globulin Therapy. Clinical Neuropharmacology, 26, 84-87. http://dx.doi.org/10.1097/00002826-200303000-00007

[10] Korinthenberg, R., Schessl, J., Kirschner, J. and Mönting Jr., S. (2005) Intravenously Administered Immunoglobulin in the Treatment of Childhood Guillain-Barré Syndrome: Arandomized Trial. Pediatrics, 116, 8-14. http://dx.doi.org/10.1542/peds.2004-1324

[11] Carpo, M., Pedotti, R., Allaria, S., et al. (1999) Clinical Presentation and Outcome of Guillain-Barré and Related Syndromes in Relation to Anti-Ganglioside Antibodies. Journal of the Neurological Sciences, 168, 78-84. http://dx.doi.org/10.1016/S0022-510X(99)00173-2

[12] Barzegar, M., Dastgiri, S., Karegarmaher, M.H. and Varshochiani, A. (2007) Epidemiology of Childhood GuillanBarré Syndrome in the North West of Iran. BMC Neurology, 7, 22. http://dx.doi.org/10.1186/1471-2377-7-22

[13] Asbury, A.K. (2000) New Concepts of Guillain-Barré Syndrome. Journal of Child Neurology, 15, 183-191. http://dx.doi.org/10.1177/088307380001500308

[14] Bradshaw, D.Y. and Jones Jr., H.R. (1992) Guillain-Barré Syndrome in Children: Clinical Course, Electrodiagnosis, and Prognosis. Muscle \& Nerve, 15, 500-506. http://dx.doi.org/10.1002/mus.880150415

[15] By Mayo Clinic Staff. Diseases and Conditions Guillain-Barré Syndrome, @1998-2015 Mayo Foundation for Medical Education and Research.

[16] Rees, J.H., Soudain, S.E., Gregson, N.A. and Hughes, R.A.C. (1995) Campylobacter jejuni Infection and GuillainBarré Syndrome. The New England Journal of Medicine, 333, 1374-1379.

http://dx.doi.org/10.1056/NEJM199511233332102

[17] Kushnir, M., Klein, C., Pollak, L. and Rabey, J.M. (2008) Evolving Pattern of Guillain-Barré Syndrome in a Community Hospital in Israel. Acta Neurologica Scandinavica, 117, 347-350. http://dx.doi.org/10.1111/j.1600-0404.2007.00949.x

[18] Landaverde, J.M., Danovaro-Holliday, M.C., Trumbo, S.P., Pacis-Tirso, C.L. and Ruiz-Matus, C. (2010) GuillainBarré Syndrome in Children Aged < 15 Years in Latin America and the Caribbean: Baseline Rates in the Context of the Influenza A (H1N1) Pandemic. The Journal of Infectious Diseases, 201, 746-750. http://dx.doi.org/10.1086/650530

[19] Hughes, R.A. and Rees, J.H. (1997) Clinical and Epidemiological Features of Guillain-Barré Syndrome. The Journal of Infectious Diseases, 176, S92-S98. http://dx.doi.org/10.1086/513793

[20] Molinero, M.R., Varon, D., Holden, K.R., Sladky, J.T., Molina, I.B. and Cleaves, F. (2003) Epidemiology of Child- 
hood Guillain-Barré Syndrome as a Cause of Acute Flaccid Paralysis in Honduras: 1989-1999. Journal of Child Neurology, 18, 741-747. http://dx.doi.org/10.1177/08830738030180110801

[21] Koul, R., Al-Futaisi, A., Chacko, A., Fazalullah, M., Nabhani, S.A., Al-Awaidy, S., Al-Busaidy, S. and Al-Mahrooqi, S. (2008) Clinical Characteristics of Childhood Guillain-Barré Syndrome. Oman Medical Journal, 23, 158-161.

[22] Rantala, H., Cherry, J.D., Shields, W.D. and Uhari, M. (1994) Epidemiology of Guillain-Barré Syndrome in Children: Relationship of Oral Polio Vaccine Administration to Occurrence. The Journal of Pediatrics, 124, 220-223. http://dx.doi.org/10.1016/S0022-3476(94)70307-8

[23] Evans, O.B. and Vedanarayanan, V. (1997) Guillain-Barré Syndrome. Pediatrics in Review, 18, 10-16. http://dx.doi.org/10.1542/pir.18-1-10

[24] Farkkila, M., Kinnunen, E., Hovi, T. and Livanainen, M. (1987) Nonintended Plasma Exchange Therapy in Poliomyelitis: Difficulties in the Differential Diagnosis of Paralytic Poliomyelitis and Polyradiculitis. Annals of Clinical Research, 19, 395-398.

[25] Jones, H.R. (1996) Childhood Guillain-Barré Syndrome: Clinical Presentation, Diagnosis and Therapy. Journal of Child Neurology, 11, 4-12.

[26] World Health Organization (1995) Field Guide for Supplementary Activities Aimed at Achieving polio Eradication. Publication WHO EPI/95.1, WHO, Geneva.

[27] Olivé, J.M., Castillo, C., Castro, R.G. and de Quadros, C.A. (1997) Epidemiologic Study of Guillain-Barré Syndrome in Children < 15 Years of Age in Latin America. The Journal of Infectious Diseases, 175, S160-S164.

[28] Jasem, J., Marof, K., Nawar, A., Khalaf, Y., Aswad, S., Hamdani, F., Islam, M. and Kalil, A. (2013) Guillain-Barré Syndrome as a Cause of Acute Flaccid Paralysis in Iraqi Children: A Result of 15 Years of Nation-Wide Study. BMC Neurology, 13, 195. http://dx.doi.org/10.1186/1471-2377-13-195

[29] McKhann, G.M., Cornblath, D.R., Griffin, J.W., et al. (1993) Acute Motor Axonal Neuropathy: A Frequent Cause of Acute Flaccid Paralysis in China. Annals of Neurology, 33, 333-342. http://dx.doi.org/10.1002/ana.410330402 